\title{
Enhancement of Luminescence Dissymmetry Factor in Nano-Segregated Phase Generated by Phase Separation between Helical Nanofilaments and Liquid-Crystalline Smectic A Phase
}

\author{
Jae-Jin Lee and Suk-Won Choi *(1) \\ Department of Advanced Materials Engineering for Information and Electronics, Kyung Hee University, \\ Yongin-shi, Gyeonggi-do 17104, Korea; jjking1443@naver.com \\ * Correspondence: schoi@khu.ac.kr; Tel.: +82-031-201-2256
}

Received: 26 September 2020; Accepted: 16 October 2020; Published: 19 October 2020

\begin{abstract}
Although several methods exist for the synthesis of circularly polarized luminescent (CPL) materials, the methods are extremely complex and tedious. In recent years, the chiral host-achiral luminescent guest method and the achiral host-achiral luminescent guest method have been employed to fabricate CPL materials; however, the main disadvantage of the latter is the small luminescence dissymmetry factor ( $\mathrm{g}_{\text {lum }}$ ) that limits the practical applications of the method. Therefore, this study reports on the enhancement of $g_{l u m}$ in a nano-segregated phase system, generated by the phase separation between helical nanofilaments (HNFs; originating from an achiral bent-core molecule) and a liquid-crystalline (LC) smectic A (SmA) phase (originating from an achiral rod-like mesogen). The observed glum value in the nano-segregated phase between the HNFs and LC SmA phase was larger than that in the nano-segregated phase between the HNFs and LC nematic $(\mathrm{N})$ phase. The enhancement of the glum value was attributed to the order parameter $(S)$ of the dye molecules in the SmA phase being larger than that in the N phase. Therefore, we concluded that the $S$ value of the fluorescent dye molecules, doped into the embedded LC phase between the HNFs, strongly influenced the glum value.
\end{abstract}

Keywords: liquid crystals; bent-core molecules; rod-like mesogens; circularly polarized luminescence; helical nanofilaments; smectic A

\section{Introduction}

The synthesis of circularly polarized luminescent (CPL) materials is extremely complicated [1]. Furthermore, the process itself is long and arduous, and cannot ensure circularly polarized emissions from the synthesized materials. In recent years, another method has been employed as a general and versatile approach for fabricating CPL materials, termed the chiral host-achiral luminescent guest method [1-3], wherein achiral luminescent guest molecules are embedded into chiral molecules that form chiral aggregates. The luminescent guest molecules are influenced by the chiral aggregates, resulting in the emission of circularly polarized light.

A mixed system, consisting of an achiral bent-core (BC) molecule and rod-like nematogen, has been reported as a promising chiroptic material [4-8]. In this system, nano-sized phase separation-between helical nanofilaments (HNF) originating from the BC molecule and the calamitic liquid-crystalline (LC) nematic $(\mathrm{N})$ phase originating from rod-like nematogen-shows high chiropticity, such as optical rotatory power or circular dichroism $[5,9,10]$. A recent study reported on an intriguing method to fabricate CPL materials using the aforementioned nano-segregated phase. The latter was blended with a fluorescent molecule (guest dye), and the CPL material was successfully obtained [11]. This was 
attributed to the helix of the HNF affecting the structure of the embedded N phase doped with the guest dye, thereby forming self-assembled chiral aggregates associated with the helix of the HNF phase, despite having a mixed system consisting of only chemically achiral molecules. The calamitic guest dyes generally obey the orientational ordering of the rod-like mesogen while mixing with rod-like mesogenic molecules [11]. An N phase that is blended with the guest dye molecule and segregated from the HNFs forms chiral aggregates; therefore, circularly polarized luminescence, attributed to the dye molecules in the chiral aggregates, can be observed [11]. Because both the host and guest in the system are chemically achiral, this method can be regarded as an achiral host-achiral luminescent guest method. The advantage of this method is the elimination of the complicated chiral molecular design necessary to fabricate CPL materials. However, this method yields an insufficient luminescence dissymmetry factor $\left(\mathrm{g}_{\text {lum }}\right)$ that restricts its practical applications. Although the $\mathrm{g}_{\text {lum }}$ value observed in this study was comparable with the values reported for low-molecular-weight chiral organic compounds in the solution phase [12], further enhancement of $g_{\text {lum }}$ is desirable for the utilization of this system in practical applications.

Therefore, to enhance the $\mathrm{g}_{\text {lum }}$ value in the aforementioned nano-segregated phase system, $(<\mathrm{HNF} / \mathrm{N}>)$ formed by the phase separation between the HNFs and LC N phase, we explored another nano-segregated phase, $\langle\mathrm{HNF} / \mathrm{SmA}>$, generated by the phase separation between the HNFs and the liquid-crystalline (LC) smectic A (SmA) phase. The glum value observed in this nano-segregated $<\mathrm{HNF} / \mathrm{SmA}>$ phase was larger than that in the nano-segregated $<\mathrm{HNF} / \mathrm{N}>$ phase. This was because the order parameter $(S)$ of the guest dye molecules, doped into the embedded LC phase between the HNFs, was strongly related to $\mathrm{glum}_{\text {lum }}$. Particularly, the enhancement of the $\mathrm{g}_{\text {lum }}$ value was attributed to the increasing $S$ value of the dye molecules in the SmA phase.

\section{Materials and Methods}

\subsection{Materials}

A mixture of $34.6 \mathrm{wt} \%$ BC molecules (P-7, synthesized by our group), $64.4 \mathrm{wt} \%$ rod-like mesogen (8OCB, Sigma-Aldrich, Seoul, Korea), and $1 \mathrm{wt} \%$ fluorescent dye (PM580, Exciton) was prepared. The mixture was dissolved in an organic solvent (chloroform) and mixed via sonication for $1 \mathrm{~h}$. Subsequently, the mixture was thoroughly dried by heating $\left(80^{\circ} \mathrm{C}, 30 \mathrm{~min}\right)$ to remove the solvent. The absence of residual solvent in the sample was examined via phase-transition temperature measurement using polarized optical microscopy (POM). In the mixture system, unique phases found in the BC molecule, such as B2 and B7, readily disappeared upon mixing of the rod-like mesogen $[8,13,14]$. Instead, the aforementioned nano-sized separation phases, such as $\langle\mathrm{HNF} / \mathrm{N}\rangle$, $<\mathrm{HNF} / \mathrm{SmA}>$, and $<\mathrm{HNF} / \mathrm{Iso}>$ were observed. The latter also denotes a nano-segregated phase, wherein the $\mathrm{BC}$ molecule is in the HNF phase and the rod-like molecule is in the Iso phase in the mixture. These nano-segregated phases were verified using POM, differential scanning calorimetry, and circularly polarized luminescence measurement. The phase-transition temperatures of $\mathrm{P}-7,8 \mathrm{OCB}$, and the mixture are summarized in Table 1, and the chemical structures of P-7, 8OCB, and PM580 are depicted in Figure 1.

Table 1. Phase-transition temperatures of $\mathrm{P}-7,8 \mathrm{OCB}$, and the mixture.

\begin{tabular}{lr}
\hline \multicolumn{1}{c}{ Materials } & Phase and Phase Transition Temperatures \\
\hline P-7 & Iso- $170{ }^{\circ} \mathrm{C}-\mathrm{B} 2-155^{\circ} \mathrm{C}-\mathrm{B} 7-144{ }^{\circ} \mathrm{C}-\mathrm{HNF}$ \\
$8 \mathrm{OCB}$ & Iso- $80{ }^{\circ} \mathrm{C}-\mathrm{N}-67{ }^{\circ} \mathrm{C}-\mathrm{SmA}-54{ }^{\circ} \mathrm{C}-\mathrm{Cryst}$ \\
Mixture & $<\mathrm{HNF} / \mathrm{Iso}>-80{ }^{\circ} \mathrm{C}-<\mathrm{HNF} / \mathrm{N}>-67{ }^{\circ} \mathrm{C}-<\mathrm{HNF} / \mathrm{SmA}>-54{ }^{\circ} \mathrm{C}$-Cryst \\
\hline
\end{tabular}

\subsection{Cell Preparation}

Two types of cells were fabricated herein: (a) $2 \mu \mathrm{m}$ thick cells consisting of two quartz substrates without surface treatment (such as rubbing) to prevent the large birefringence that often impedes the circularly polarized luminescent measurement, and (b) $4 \mu \mathrm{m}$ thick planar cells consisting of two 
quartz substrates coated with a homogenous aligned layer, with unidirectional rubbing treatment, for polarized emission intensity observations to determine the $S$ value of the guest dye molecules doped into the LC phase. The mixture was inserted into the cell in an isotropic state and the cell was slowly cooled to room temperature.

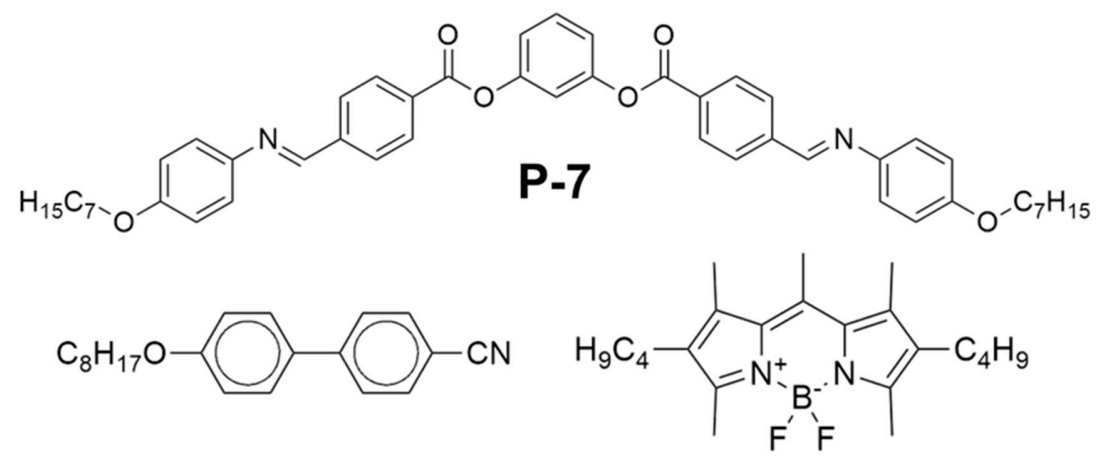

80CB

PM580

Figure 1. Chemical structures of P-7, 8OCB, and PM580.

\subsection{Circularly Polarized Luminescence Measurement}

Light (wavelength of $525 \mathrm{~nm}$ ) was used as the optical pumping source and the emission output was modulated using a photoelastic modulator (PEM). The polarization-modulated signal was passed through a linear polarizer and was thereby converted into an intensity-modulated signal. Subsequently, it was detected using a photomultiplier tube (PMT). The AC component of the PMT output was analyzed using a lock-in amplifier, which was locked with the reference frequency signal from the PEM. The CPL spectra were calculated from the wavelength dependence of the AC and DC components and the phase of the modulated signal. The details are provided in References $[4,10,15]$. The glum value was evaluated using the following correlation:

$$
\mathrm{g}_{\text {lum }}=2\left(I_{\text {left }}-I_{\text {right }}\right) /\left(I_{\text {left }}+I_{\text {right }}\right) \text {, }
$$

where $I_{\text {left }}$ and $I_{\text {right }}$ are the magnitudes of the left- and right-circularly polarized components, respectively. If a material emits completely left- or right-circularly polarized light, the value of $g_{\text {lum }}$ would be maximized (equal to 2).

\subsection{Polarized Emission Intensity Observations}

Absorption intensities of the cell containing the mixtures were measured as a function of the sample rotation angle at a given temperature. The $S$ value of the dye was calculated using the following equation:

$$
S=\left(\left(\mathrm{A}_{\text {para }} / \mathrm{A}_{\text {perpen }}\right)-1\right) /\left(\left(\mathrm{A}_{\text {para }} / \mathrm{A}_{\text {perpen }}\right)+2\right),
$$

where $A_{\text {para }}$ and $A_{\text {perpen }}$ represent the absorption maximum $\left(\lambda_{\max }=570 \mathrm{~nm}\right)$ of the guest dye for the light that was polarized parallel and perpendicular to the rubbing direction, respectively.

\section{Results and Discussion}

Figure 2a shows the typical CPL spectra of $<\mathrm{HNF} / \mathrm{SmA}>\left(58^{\circ} \mathrm{C}\right),<\mathrm{HNF} / \mathrm{N}>\left(75^{\circ} \mathrm{C}\right)$, and $<\mathrm{HNF} / \mathrm{Iso}>$ $\left(90^{\circ} \mathrm{C}\right)$. The $\mathrm{g}_{\text {lum }}$ value (at $570 \mathrm{~nm}$ ), as a function of temperature, is shown in Figure $2 \mathrm{~b}$. The evaluated glum values exhibited distinct changes near phase-transition temperatures of $54{ }^{\circ} \mathrm{C}$ (from crystalline to $<\mathrm{HNF} / \mathrm{SmA}>$ ), $67^{\circ} \mathrm{C}$ (from $<\mathrm{HNF} / \mathrm{SmA}>$ to $<\mathrm{HNF} / \mathrm{N}>$ ), and $80^{\circ} \mathrm{C}$ (from $<\mathrm{HNF} / \mathrm{N}>$ to $<\mathrm{HNF} / \mathrm{Iso}>$ ). This was consistent with the phase-transition temperatures of pure $8 \mathrm{OCB}$, indicating that the nanoscale phase segregations occurred between P-7 and 8OCB. The evaluated $g_{\text {lum }}$ values in $<\mathrm{HNF} / \mathrm{N}>$ in the P-7 
and $8 \mathrm{OCB}$ mixtures were $6 \times 10^{-3}-8 \times 10^{-3}$, comparable to those in a similar $<\mathrm{HNF} / \mathrm{N}>$ mixed system reported previously [11]. Meanwhile, the glum value in $<\mathrm{HNF} / \mathrm{SmA}>$ was relatively larger than that in $\langle\mathrm{HNF} / \mathrm{N}\rangle$. The evaluated glum values in $<\mathrm{HNF} / \mathrm{SmA}>$ were $1.0 \times 10^{-2}-1.1 \times 10^{-2}$. This result indicated that the glum value strongly relied on the polymorphism of the rod-like mesogen in the mixture. This was because the fluorescent dye molecules residing in LC phases (N or SmA) segregated from the HNFs of the BC molecules. Particularly, the N or SmA phase blended with the dye molecules and segregated from the HNFs, resulting in a chiral superstructure; therefore, circularly polarized luminescence, originating from the dye molecules confined in the chiral superstructure was observed.

a)

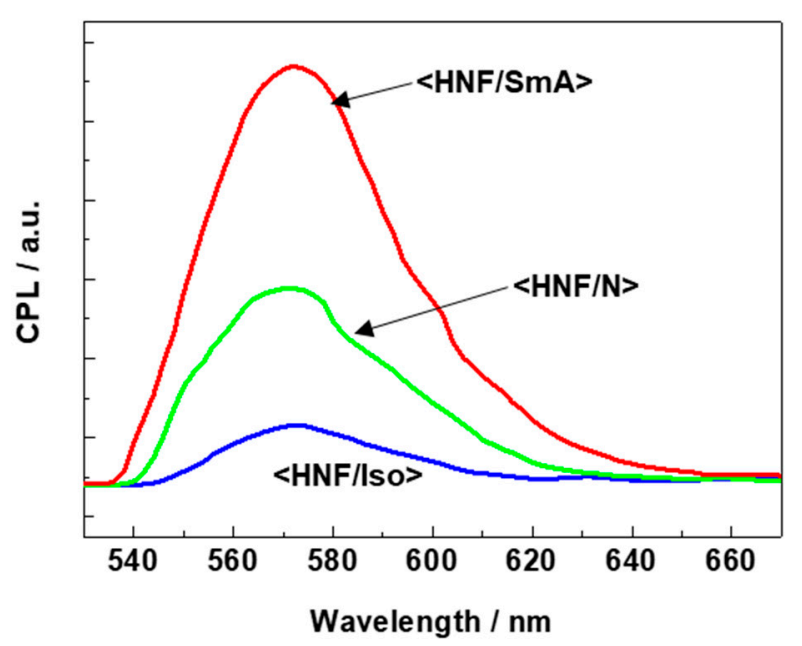

b)

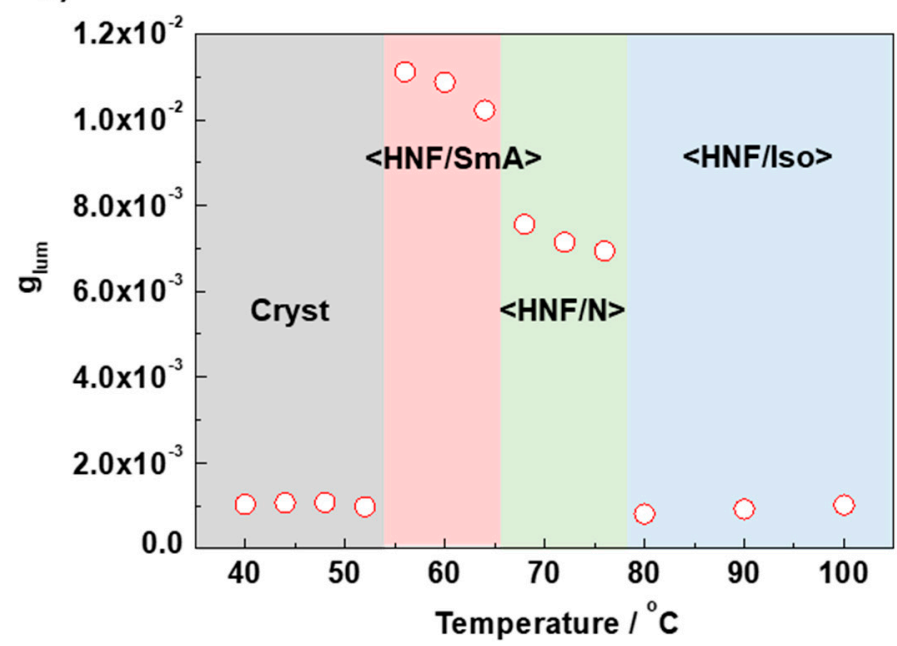

Figure 2. (a) Typical circularly polarized luminescence spectra of $<\mathrm{HNF} / \mathrm{SmA}>\left(58{ }^{\circ} \mathrm{C}\right)$, $<\mathrm{HNF} / \mathrm{SmA}>\left(75^{\circ} \mathrm{C}\right)$ and $<\mathrm{HNF} / \mathrm{Iso}>\left(90^{\circ} \mathrm{C}\right)$. (b) glum values (at $570 \mathrm{~nm}$ ) at different temperatures. $\mathrm{HNF}=$ helical nanofilaments.

To explain the enhancement of $\mathrm{g}_{\text {lum }}$ in $\langle\mathrm{HNF} / \mathrm{SmA}\rangle$ compared to that in $\langle\mathrm{HNF} / \mathrm{N}\rangle$, we evaluated the degree of alignment (i.e., $S$ ) of the guest dye in the host $\mathrm{N}$ and SmA phases [16]. Figure 3 shows the polar plots of the absorption intensities for the $8 \mathrm{OCB}$ blended with $1 \mathrm{wt} \%$ dye, as a function of the sample rotation angle at the $\mathrm{N}\left(65^{\circ} \mathrm{C}\right)$ and SmA phase $\left(75^{\circ} \mathrm{C}\right)$ in the planar LC cells. The perpendicular direction corresponds to the rubbing direction. The evaluated $S$ value of the dye molecule blended into the $\mathrm{N}$ and SmA phase was 0.4 and 0.55 , respectively (i.e., the $S$ value of the dye molecule that blended into the SmA phase was larger than that of the dye molecule blended into 
the $\mathrm{N}$ phase). Therefore, the enhancement of $\mathrm{g}_{\text {lum }}$ could be attributed to the increasing $S$ value of the dye molecules in the SmA phase.

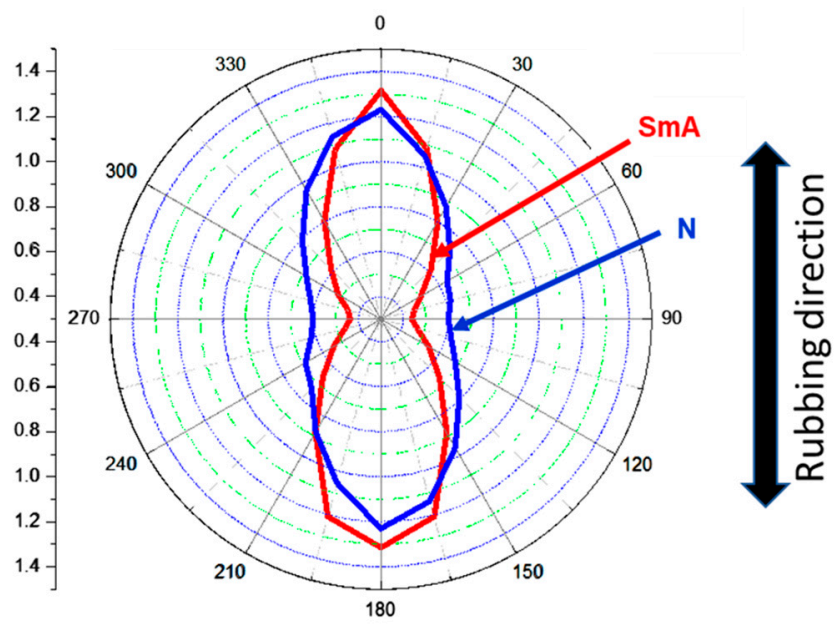

Figure 3. Polar plot of the polarized absorption intensity of the blended dye molecule (PM580; $1 \mathrm{wt} \%$ ), as a function of the sample rotation angle in the $\operatorname{LCN}\left(75^{\circ} \mathrm{C}\right)$ and $\operatorname{SmA}\left(58^{\circ} \mathrm{C}\right)$ phases in the planar liquid-crystalline (LC) cells.

However, preferential circularly polarized luminescence, with left- or right-handedness, was randomly observed due to degeneracy of the helical handedness of the nanofilaments which originated from the achiral BC molecules. This was because the achiral BC molecules self-organized into two chiral domains, comprising of HNFs, which possessed an opposite helical handedness owing to a lack of chirality at the molecular level. Several methods have been implemented to overcome this disadvantage, including an extrinsic chiral platform method, the details of which will be reported in a future study.

\section{Summary}

In this work, we observed an enhancement in the glum value in a nano-segregated phase system, generated by the phase separation between HNFs (originating from an achiral BC molecule) and a LC SmA phase (originating from an achiral rod-like mesogen). The glum value observed in the nano-segregated phase $<\mathrm{HNF} / \mathrm{SmA}>$ was larger than that in the nano-segregated $<\mathrm{HNF} / \mathrm{N}>$ phase. This is because glum was closely related to the $S$ value of the dye molecules doped into the LC phase. Particularly, the $S$ value of the dye molecule blended into the SmA phase was larger than that of the dye molecule blended into the $\mathrm{N}$ phase. Therefore, the study findings provide a practical method to fabricate CPL materials in an achiral host-achiral luminescent guest system.

Author Contributions: Investigation, J.-J.L.; writing—original draft preparation, J.-J.L., S.-W.C.; writing一review and editing, S.-W.C.; supervision, S.-W.C.; funding acquisition, S.-W.C. All authors have read and agreed to the published version of the manuscript.

Funding: This research was funded by the National Research Foundation of Korea, grant number NRF-2019R1F1A1058751 and NRF-2020R1A6A1A03048004.

Acknowledgments: We would like to thank Fumito Araoka (RIKEN, Japan) for discussing and assisting us with the circularly polarized luminescence measurement. We would also like to thank the Core Facility Center for Analysis of Optoelectronic Materials and Devices, in Kyung Hee University (Yongin, Korea), for supporting us during the other measurements.

Conflicts of Interest: The authors declare no conflict of interest. 


\section{References}

1. Sang, Y.; Han, J.; Zhao, T.; Duan, P.; Liu, M. Circularly Polarized Luminescence in Nanoassemblies: Generation, Amplification, and Application. Adv. Mater. 2019, 31, 1900110. [CrossRef]

2. Goto, T.; Okazaki, Y.; Ueki, M.; Kuwahara, Y.; Takafuji, M.; Oda, R.; Ihara, H. Induction of Strong and Tunable Circularly Polarized Luminescence of Nonchiral, Nonmetal, Low-Molecular-Weight Fluorophores Using Chiral Nanotemplates. Angew. Chem. Int. Ed. 2017, 56, 2989-2993. [CrossRef] [PubMed]

3. Shi, Y.; Duan, P.; Huo, S.; Li, Y.; Liu, M. Endowing Perovskite Nanocrystals with Circularly Polarized Luminescence. Adv. Mater. 2018, 30, 1705011. [CrossRef] [PubMed]

4. Lee, J.-J.; Kim, B.-C.; Choi, H.-J.; Bae, S.; Araoka, F.; Choi, S.-W. Inverse Helical Nanofilament Networks Serving as a Chiral Nanotemplate. ACS Nano 2020, 14, 5243-5250. [CrossRef] [PubMed]

5. Jeon, S.-W.; Kim, D.-Y.; Araoka, F.; Jeong, K.-W.; Choi, S.-W. Nanosegregated Chiral Materials with Self-Assembled Hierarchical Mesophases: Effect of Thermotropic and Photoinduced Polymorphism in Rodlike Molecules. Chem. Eur. J. 2017, 23, 17794-17799. [CrossRef] [PubMed]

6. Kim, K.; Kim, H.; Jo, S.-Y.; Araoka, F.; Yoon, D.K.; Choi, S.-W. Photomodulated Supramolecular Chirality in Achiral Photoresponsive Rodlike Compounds Nanosegregated from the Helical Nanofilaments of Achiral Bent-Core Molecules. ACS Appl. Mater. Interfaces 2015, 7, 22686-22691. [CrossRef] [PubMed]

7. Jeon, S.-W.; Choi, H.-J.; Bae, J.-H.; Kim, B.-C.; Choi, S.-W. Photomodulating Chiroptic Behaviors in Nanosegregated Mesophase from a Mixture System Consisting of Nonchiral Bent-Core and Photo-Responsive Rod-Like Mesogens. J. Inf. Disp. 2018, 19, 129-133. [CrossRef]

8. Park, W.; Yoon, D.K. Orientation Control of Helical Nanofilament Phase and Its Chiroptical Applications. Crystals 2020, 10, 675. [CrossRef]

9. Otani, T.; Araoka, F.; Ishikawa, K.; Takezoe, H. Enhanced Optical Activity by Achiral Rod-Like Molecules Nanosegregated in the B4 Structure of Achiral Bent-Core Molecules. J. Am. Chem. Soc. 2009, 131, 12368-12372. [CrossRef] [PubMed]

10. Le, K.V.; Takezoe, H.; Araoka, F. Chiral Superstructure Mesophases of Achiral Bent-Shaped Molecules-Hierarchical Chirality Amplification and Physical Properties. Adv. Mater. 2017, $29,1602737$. [CrossRef] [PubMed]

11. Kim, B.-C.; Choi, H.-J.; Lee, J.-J.; Araoka, F.; Choi, S.-W. Circularly Polarized Luminescence Induced by Chiral Super Nanospaces. Adv. Funct. Mater. 2019, 29, 1903246. [CrossRef]

12. Han, J.; Duan, P.; Li, X.; Liu, M. Amplification of circularly polarized luminescence through triplet-triplet annihilation-based photon upconversion. J. Am. Chem. Soc. 2017, 139, 9783-9786. [CrossRef] [PubMed]

13. Takanishi, Y.; Shin, G.J.; Jung, J.C.; Choi, S.W.; Ishikawa, K.; Watanabe, J.; Takezoe, H.; Toledano, P. Observation of Very Large Chiral Domains in a Liquid Crystal Phase Formed by Mixtures of Achiral Bent-Core and Rod Molecules. J. Mater. Chem. 2005, 15, 4020-4024. [CrossRef]

14. Araoka, F.; Sugiyama, G.; Ishikawa, K.; Takezoe, H. Highly Ordered Helical Nanofilament Assembly Aligned by a Nematic Director Field. Adv. Funct. Mater. 2013, 23, 2701-2707. [CrossRef]

15. Riehl, J.P.; Richardson, F.S. Circularly Polarized Luminescence Spectroscopy. Chem. Rev. 1986, 86, 1-16. [CrossRef]

16. Araoka, F.; Shin, K.-C.; Takanishi, Y.; Ishikawa, K.; Takezoe, H.; Zhu, Z.; Swager, T. How doping a cholesteric liquid crystal with polymeric dye improves an order parameter and makes possible low threshold lasing. J. Appl. Phys. 2003, 94, 279-283. [CrossRef]

Publisher's Note: MDPI stays neutral with regard to jurisdictional claims in published maps and institutional affiliations.

(C) 2020 by the authors. Licensee MDPI, Basel, Switzerland. This article is an open access article distributed under the terms and conditions of the Creative Commons Attribution (CC BY) license (http://creativecommons.org/licenses/by/4.0/). 